\title{
ASSISTÊNCIA À MÃE DE RECÉM-NASCIDO INTERNADO NA UTI NEONATAL: EXPERIÊNCIAS, SENTIMENTOS E EXPECTATIVAS MANIFESTADAS POR MÃES.*
}

\author{
Maria Aparecida de Jesus Belli"
}

BELLI. M. A de J. Assistência à mae de recém-nascido internado na UTI neonatal: experiências, sentimentos e expectativas manifestadas por mães. _Rev. Esc. Enf. USP. v.29 . n.2. p. 193.210. ago. 1995

Este estudo teve por objetivo verificar as experiencias, sentimentos e expectativas das mães de recém-nascidos internados na UTI neonatal. A população constou de 20 mães de recém-nascidos internados na UTI neonatal de três hospitais-escola da cidade de São Paulo. Os dados foram coletados por meio de entrevista com as mães utilizando-se um formulário com perguntas fechadas $e$ abertas. Verificou-se que a maioria das mães manteve pouca ou nenhuma interação com o filho após o nascimento; o contato visual foi o mais referido ao longo da permanéncia do recémnascido na UTI neonatal; todas manifestaram o desejo de participar dos cuidados ao filho, além de apresentar necessidades relacionadas com as informações sobre o estado de saíde do bebê. o contexto da UTI neonatal e os elementos da equipe hospitalar. Evidenciou-se, também. uma gama de sentimentos e uma variedade de motivos que determinam as necessidades $e$ as expectativas das mães que vivenciam esta situação.

I'NITERMOS: Interação mãe-filho. Enfermagem neonatal. I'nidade de Terapia Intensiva neonatal. Recém-nascido de alto risco

\section{INTRODUÇÃO}

Nas últimas decadas, bebês recem-nascides de alto risco têm conseguido aumentar suas possibilidades de solorevida gracas ao surgimento de unidades de euidados intensivos neonatais. Este modelo. embora tenha se de.

\footnotetext{
- Este artigo é parte da Dissertaçáo de Mestrado apresentada à Escola de Enfermagem da USP.

** Enfermeira. Mestre em Enfermagem. Professor Assistente do Departamento de Enfermagem Materno- Infantil e Psiquiátrica da Escola de Enfermagem da USP.
} 
senvolvido marcadamente nos aspectos tecnologicos, na prática assistencial. muitas vezes, ele tem desconsiderado a sua unidade biopsicossocial e espiritual, pois tem contribuído para a separação do binômio mãe-recém-nascido. Tal fato dificulta ou afeta significativamente o processo de vinculação mãe. filho.

Assim. por considerarmos de fundamental importância na assistência ao recém-nascido em estado crítico e a sua família a abordagem que vise o favorecimento da interação precoce e continua entre mãe e filho após o nascimento, ó que nos propomos a realização este estudo.

MALIOONADO (1984) destaca que uma série de estudos tem tentado comprovar a existência de um período sensivel para a mãe. nas primeiras horas apos o parto, por ser o momento mais propício para a formação de um vínculo afetivo especial com o bebê. Considera ainda esse período como aquele em que se verificaria a presença de uma maior sensibilidade para a mãe interagir com o recem-nascido e formar um vínculo com ele.

Existem evidencias consideráveis de que, no momento do nascimento e durante meses a fio, as necessidades maternas de contato mãe-filho excedem as do bebê. A necessidade de contato íntimo materno e muito maior o consideravelmente mais prolongada. servindo não so a importantes funçoes psicologicas como a muitas de natureza fisiologica do periodo puerperal (MON'TAGÚ, 1988).

Quando a mãe se vincula com seu filho, ela estabelece um compromisso emocional com a criança. o qual pode ser a força fundamental que estimula a mãe a cuidar do filho. Sem este compromisso por parte de quem cuida do bebê. as probabilidades de ele crescer e desenvolver-se adequadamente são menores. A ausência deste compromisso pode gerar perturbaçós de vinculação e esta perturbação pode constituir-se em uma das circunstâncias que leva a criança a ser maltratada e a não se desenvolver adequadamente $\left(\mathrm{K} \Lambda \mathrm{N}\left(x_{1} .1982\right)\right.$.

Há ocasiōes, entretanto, que este vínculo mãe-filho o prejudicado. ou rompido abruptamente. principalmente quando a sobrevivência do neonato está em risco. Isso ocorre em situações de parto prematuro ou de nascimento de bebê de alto risco. que precisa permanecer na Unidade de Terapia Intensiva neonatal (UTI neonatal), longe do contato com a mãe.

Diante dessa situação surge uma scerie de problemas. tais como: privação da manutenção do vínculo mãe-filho: preocupação das mães pela recuperação e sobrevivencia do filho: sentimento de culpa derivado desta situacão e outros como os fatores sócio-económicos. que podem influenciar a estabilidade familiar.

REICHLE (1975) afirma que a simples menção dos termos cuidados intensicos ou estado crílico traz a mente situaçōes negativas. $A$ intervenção 
em UTI significa normalmente para o paciente e seus familiares uma piora das condições físicas, colocando o paciente em proximidade com a morte.

Para ZIEGHL; CRANLEY (1985b), a primeira visita a U'TI neonatal pode ser deprimente para os pais. O recém-nascido tem, com freqüência, pelo menos uma infusão endov enosa. fios ligados para monitorização, sonda endotraqueal acoplada a um respirador e. na maioria das vezes, permanece confinado em incubadora. Hsses autores, afirmam que os pais necessitam receber apoio do médico e do enfermeiro e uma explicação realista do prognóstico. para que possam compreender a doença do seu bebê e o porque de todo o equipamento existente para os cuidados que ele está recebendo.

RAMOS: MORAES (1976) e IRWIN; ILLOYI)-STIIL , (1987) indicam que parte importante do tratamento da criança o reduzir a ansiedade dos pais por meio do oferecimento de apoio, para ajuda-los na expressão de seus sentimentos. Se a mãe ou o pai experimentam um relacionamento positivo com um profissional no hospital. seu nível de ansiedade diminui e sua percepcão da situação torna-se mais acurada.

Ainda. em se tratando da assistência a família de recém-nascido de alto risco. a equipe hospitalar deverá - mesmo dentro das circunstâncias especiais de cuidados intensivos - facilitar ao máximo as possibilidades de contato entre a mãe o o bebê. Para isso, a mãe deverá ter livre acesso à unidade neonatal podendo tocar e acariciar ofilho. mesmo sem poder pega-lo no colo quando ainda está em estado grave.

A manutenção do vínculo màc-filho oum dos aspectos da assistência obstétrica e neonatal que tem merecido especial atenção ao longo de nossa atividade profissional. Temos experiência vivenciada como membro de um grupo multiprofissional em um "Programa de Pais Participantes". que foi desenvolvido em um berçário de uma maternidade pública e cujo principal objetivo era a manutenção da interação mãe-filho, quando o recém-nascido permanecia no berśário após a alta hospitalar da mãe. Neste contexto, verificou-se que esta forma de interaça promoveu maior envolvimento tanto dos pais como dos elementos da equipe multiprofissional que assistia a esses recém-nascidos (BELLL, 1988).

Considerando que, não obstante o aparato tecnológico que envolve uma U'Tl neonatal. as mães têm condições e o direito de participar da assistência de seus filhos, continuamos a realizar estudos sobre a temática (BELLIJ; TSUNECHIR( ). 1989, 1992). Esta crença tambem é enfatizada por ZIEGEL; CRANLEY (1985a), ao afirmarem que os pais devem ser considerados como membros da equine de assistência e não como visitantes. Da mesma forma, VERNY: KELILY (1991), alem de apontarem o direito dos pais, consideram que estes devem insistir para participar dos cuidados ao filho. mesmo àqueles confinados em U'Tl. 
Na revisão bibliográfica sobre o assunto em pauta. encontramos um estudo realizado por FISER et al (1981) que forneceu algum subsídio para a elaboração desta pesquisa. E'stes autores realizaram uma investigação com vinte e dois pais de crianças internadas em uma UTI pediátrica, com a finalidade de identificar as "intervenções" que ajudaram a diminuir o estresse destes pais. As intervenções identificadas relacionavam-se a: 1. Informação sobre a unidade - rotinas e procedimentos hospitalares: condições, tratamento e evolução da doença do filho; 2 . Relacionamento com os membros da equipe hospitalar - conhecimento de médicos e enfermeiras que são responsáveis pelo cuidado do seu filho; disponibilidade constante dos mesmos; 3. Serviços para conforto dos pais - sala de espera especial para U'l'I. lanchonete ou acomodações que permitam o repouso e o preparo de refeiçóes dos pais enquanto o filho permanece na UTI; e 4. Participação dos pais - visita liberada durante 24 horas do dia e ampla oportunidade para participação do cuidado do filho. Os autores consideraram que este último item merece estudos posteriores.

Conscientes dessa situação crítica que envolve a assistência às mães de recém-nascidos internados na U'TI neonatal, consideramos relevante desenvolver um programa sistematizado de assistência a essas mães. Para elaborar esse programa, entendemos que ê de fundamental importância conhecer as experiências, sentimentos e expectativas sentidas pelas mães de recém-nascido internados na UTI neonatal.

É relevante e necessário entender qual o papel das mães cujos filhos permanecem na UTI neonatal, recebendo os cuidados e a atenção de outras pessoas que não as suas mães. () que essas mães têm feito nos hospitais onde o permitida a sua entrada na UTI neonatal? É permitido a elas alguma forma de participaça nos cuidados? Flas querem participar no cuidado?

Para responder a essas indagaçōes, propusemo-nos a realizar o presente estudo, a fim de obter subsídios para elaborar um programa de assistência às mães destes recém-nascidos.

\section{OBJETIVOS}

\section{Objetivo geral:}

- oferecer aos enfermeiros. que atuam nas áreas de obstetrícia e neonatologia, subsidios que lhes permitam, dentro de suas areas de competência, promover modificações no sistema de assistência de enfermagem ao binômio mãe-recém-nascido de alto risco. no sentido de que o período de internação da criança na U'II neonatal não seja motivo de privação do vínculo mãe-filho. 


\section{Objetivo específico:}

- verificar as experiências, sentimentos e expectativas das mães de recém-nascidos internados na U'Tl neonatal.

\section{METODOLOGIA}

Liste o um estudo descritivo exploratório solore as experiências. sentimentos e expectativas das mães de recem-nascidos internados na Unidade de Terapia Intensiva neonatal (U'TI neonatal).

() estudo foi realizado em maternidades de três hospitais públicos da cidade de São Paulo. Lissas maternidades foram selecionadas porque perteneem a instituicões que funcionam como hospilais de ensino. e os berçários contam com area destinada a cuidados de reeem-nascidos em estado crítico. denominada U'Tl neonatal. Nlem disso. são campos de prática para os estudantes que cursam disciplinas da área de enfermagem obstétriea e neonatal do (Jurso de Ciraduação em Enfermagem da liscola de Enfermagem da Universidade de São P'aulo (LEUS'P).

Fizeram parte deste estudo 20 mães de recem-nascidos internados na U'TI neonatal. no período de janeiro a fevereiro de 1990 . das instituicóes referidas.

Foram incluídas na população mães que atenderam aos seguintes eritérios: 1. tor dado a luz no Centro (O)stétrieo de uma maternidade campo de estudo: 2. estar com of filho internado na U'Tl neonatal há 48 horas no míni. mo: 3. não ser portadora de doenca infecto-eontagriosa que a impessibilitasse de entrar na Unidade Neonatal.

() instrumento utilizado para coleta de dados foi um formulário constituido por perguntas semi-abertas e alortas. alem de um item "outros". com a finalidade de possibilitar a manifestagào de qualquer aspecto não contemplado nas perguntas formuladas.

Para o estudo, portanto utilizou-se um formulário. destinado as mães dos recem-nascidos. que consta de duas partes:

\section{Parte I. Dados de identificação da mãe e do recém-nascido}

Incluíram-se dados que identificam as mães como idade. escolaridade. ocupacão. meio de locomocão. Constaram lambem os seguintes dados gerais de interesse para a caracterizaça desta população: vive com o pai da criança ou pessoa com quem vive. paridade. número de filhos vivos e experiência 
anterior com filho internado na U'TI neonatal. Para identificaça do recemnascido, obtivemos dados como data de nascimento. tipo de parto. sexo, idade gestacional, peso, índice de $\Lambda$ pgar. data da internação na U'TI neonatal, local de procedência e tempo de vida no momento da entrevista.

\section{Parte II. Dados relativos às experiências, sentimentos e expectativas}

\section{das mães de recém-nascidos internados na UTI neonatal.}

Incluíram-se dados quanto a informação das mães sobre a internação do filho na UTI neonatal, o estado de saúde do bebê, as normas e rotinas de funcionamento da maternidade, berçário o UTI neonatal. os aparelhos utilizados pela criança e as pessoas que cuidam do bebê: interação mãe-filho. considerando o contato visual e tátil e a participação no cuidado do bebê durante a internação: e a ajuda as mães.

()s dados foram coletados através da técnica de entrevista com as mães dos recém-nascidos, obedecendo-se aos seguintes passos: 1. verificasão. pelo prontuário do recém-nascido, da mãe que atende aos critérios estabelecidos: 2. apresentação a mãe. explicando a finalidade do estudo. solicitando a sua colaboração e assegurando o anonimato: 3. preenchimento do formulário. anotando as respostas durante a entrevista: 4. leitura das respostas ao final da entrevista, para avaliação das informações obtidas: 5 . agradecimento pela participação no estudo e forn ecimento de todos os esclarecimentos solicitados e ou necessários.

\section{RESULTADOS E DISCUSSÃO}

\section{Caracterização da população de mães e de recém-nascidos.}

$\Lambda$ população de mães do presente estudo encontrava-se em sua maioria $(80.0 \%)$ na faixa etária de menos de 25 anos. e dentre estas um número consideravel daquelas com menos de 20 anos.

Como conseqüencia da gravidez na adolescência. a literalura registra maior morbidade e mortalidade materna. baixo peso ao nascer o prematuridade nos filhos de mães muito jovens e riscos mais elevados de morbidade e mortalidade infantil, problemas que podem ser minimizados quando controlados por uma atença pró-natal adequada e pelo acompanha-

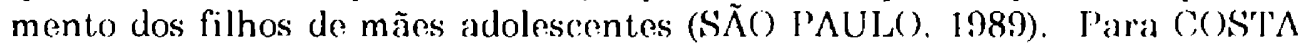
(1990). 6 oportuno ressaltar que a função procriadora tem implicacões mais complexas não só no que di\% respeito à esfera biologica propriamente dita. 
mas, sobretudo, aos aspectos psíquicos e sociais. Segundo o autor, a adoles. cente pode encontrar-se plenamente madura no seu soma e até com sua capacidade biológica em grau máximo de plenitude, porêm não acompanha o desenvolvimento paralelo da parte psíquica e social.

Já com relação à paridade, constatamos que a maioria das mães $(60,0 \%)$ eram de primíparas. Cabe considerar que em se tratando de mães de recom. nascidos internados em UTI neonatal, onde reações emocionais como, ansiedade, angústia e sentimento de culpa são comumente manifestadas, estas têm sua condição agravada pelo fato de ser o primeiro filho.

Os dados referentes à escolaridade retratam uma população de mães de pouca instrução formal ( $1^{\circ}$ grau incompleto - $\left.65,0 \%\right)$. Embora isso não possibilite estimar a capacidade da mãe para o aprendizado de alguns cuidados a serem executados com o filho internado na UTI neonatal, deve ser considerado esse fato ao se estabelecer estrategias de ensino.

Os resultados relativos à ocupaça nos mostram mães "dona de casa" (60.0\%) e trabalhadoras com vínculo empregatício (10.0\%). So considerarmos que a instituição da licença maternidade está garantida para a mulher com emprego formal (BRASlL, 1988), as mães envolvidas nesse estudo teriam disponibilidade para permanecer junto ao filho durante o periodo de internação.

Considerando que em grandes centros urbanos como São Paulo, a distância da residência o o hospital e problemas de tráfego podem dificultar o acesso da clientela aos serviços. este fato se evidenciou para as mães do presente estudo: a maioria delas $(85.0 \%)$ dependia de transporte coletivo e apenas duas mães. por residirem proximo a maternidade. puderam se dirigir ao hospital a pe.

Quanto aos filhos recem-nascidos, os dados encontrados mostram uma populaça eminentemente de bebês de alto risco ao considerarmos a adequação da idade gestacional ao peso de nascimento. $A$ grande maioria dos recémnascidos deste estudo apresentava peso ao nascer menor que 2500 gramas $(80.0 \%)$ e foram classificados como prétermo ou imaturos $(\mathbf{8 5 . 0 \% )}$. BA'TA(ALIA: LUBCHENC() (1967) salientam a incontestavel importância do peso ao nascimento em predizer problemas em neonatos. Elaboraram os diagramas de crescim ento intra-uterino de Colorado (US $\Lambda$ ), largamente utilizado para determinar a adequação da idade gestacional do recém-nascido e do peso de nascimento. Para BATACILIA: IUBCHENCO (1967), SULLIVAN et al (1979), (CRANLEY (1983) ? IJA P()IAN et al (1984), o conhecimento da idade gestacional do recém-nascido contribui para fazer sua avaliação e também permite a identificação precoce de sua vulnerabilidade ao novo meio ambiente.

Observa-se. ainda atraves da avaliação da vitalidade dos recém-nasci- 
dos ao nascimento, pelo metodo de Apgar, que a população estudada era essencialmente de crianças moderadamente ou gravemente deprimidas no primeiro minuto de vida e que a metade se manteve nessa condição no quinto minuto.

Esses dados, aliados as condições anteriormente mencionadas refor. cam. a afirmação de que os recem-nascidos necessitavam de cuidados intensivos logo após o nascimento. to importante considerar este aspecto, pois não e raro observar admissões injustificadas de recem-nascidos na U'TI determinadas apenas por suas condições pré-natais, o que tem levado muitas mães e bebês a sofrimentos desnecessários.

Com relação a idade dos bebês no momento da entrevista 9 recém-nas. cidos $(45.0 \%)$ tinham entre 2 e 3 dias de vida. L̇m correspondência as mães se encontravam no período de poss-parto, denominado de "fase de reabastecimento" do puerpério. que se caracteriza por passividade e dependencia por parte da mãe que necessita de atendimento de suas necessidades (RUBIN. 1961. ZIE(AEL: CRANLEY. 1985a). (Jutros 8 recem-nascidos $(40.0 \%)$ do cestudo estavam entre o terceiro e o décimo dia de vida, o que coincide com a "fase de participação" do puerpério. o qual transcorre para a máe em clima de forte desejo de cuidar de seu filho, aliado a certa ansiedade causada pola insegurança quanto a sua capacidade em assumir novas responsabilidades. bem como pelos sentimentos ambivalentes em relação ao bebé.

\section{Análise dos diferentes aspectos referentes à assistência às mães de recém-nascidos internados na UTI neonatal.}

\subsection{Interacão mãe.filho}

Para \%IE(XEL: (XRANLEY (1985a). as mães devem ver ofilho ao nascer. mesmo que seja por alguns segundos. Para essas autoras. essa breve visão do filho poderá ajudar as mães a perceberem a realidade da situaceão e muitas vezes dissipar fantasias sohre a aparência da criança. que noderáa ser mais assustadora que a realidade.

No que concerne a interação mae e recem-nascido. verificamos que mais da metade das mães ( 11 màes - 55.0\%) do estudo não estiabeleceram nenhuma forma de interaça com o filho logo após o nascimento. Considerando que para os elementos da equipe da sala de parto. em greral, a condição física do recém-nascido o priorizada. isso pode ser um dos motivos pelo qual muitas mães de recém-nascidos em estado grave são privadas ate do contato visual (om o filho.

Algumas manifestações verbais emitidas pelas mães revelam um sentimento de frustração pelo fato de terem sido privadas do eontato com of filho recem-nascido, tais como "A gente espert lanto lempo ..."; "É sonho de toda 
mãe"; "Se assim que nasce, se o nenê sente a presença da mãe é importante"; "Deve dar emoção tocar uma coisinha que é sua".

Essa situação se perpetua se considerarmos que um número significativo de mães $(40,0 \%)$ manteve o primeiro contato visual com o filho somente apos transcorridos 24 horas do nascimento.

Quanto as principais justificativas apresentadas pelas mães para o atraso significativo entre o nascimento e a primeira visita ao recem-nascido, te. mos a "limitação física materna" e a "restrição no berçário para entrar na U'TI neonatal".

Desstacamos alguns comentários feitos pelas mães em relação a algumas restriçoes para entrada na U'TI neonatal: "A funcionória disse que era para subir no berçário somente depois das duas e meia"; "Não entrei por causa que näo era horário de visila"; "Não entrei na UTI, quando disseram que estaca lá pensei que não pudesse entrar... visitei ela e só via pelo vidro (visor da l'Tl neonalal)".

Einquestionavel a importância o a necessidade de interação precoce e contínua entre as mães e o recem-nascido apos o nascimento. No entanto. como já foi mencionado, no caso de bebê prematuro. doente ou com malformação, verificamos que este processo de vinculação pode estar prejudicado. não só na sala de parto. mas por um período indeterminado. uma vez que o recem-nascido de alto risco necessita de cuidados especiais na unidade neonatal. Isto se confirma quando verificamos que a maioria dos recém-nascidos (75.0\%) foi encaminhada diretamente da Unidade de Centro ()bstetrico para a U'TI neonatal.

KI AUS: KENNEL (1978) citam que em eertas ocasiones o inevitavel que a mãe veja seu beloc antes de ser levado à UTI neonatal. lisses aulores sugerem que mães de recem-nascides pretermo vejam algumas fotos de neonatos prematuros. como uma forma de atenuar um pouco a discrepancia entre o que ela imagina e o verdadeiro aspecto de um recem-nascido pretermo. Assim, ao ver o filho, o impacto poderá ser menor.

Quando indagamos junto às 11 mães $(55.0 \%)$ do estudo quanto as razões da privação de qualquer tipo de interação com o filho recem-naseido logo após o nascimento. verificamos que seis delas não souberam referiro motivo. Dentre aquelas que referiram alguma razão para a privaça denotamos. que essa razão estava relacionada a condição de saúde da criança.

Constatou-se ainda que com relaça a permanêneia da mãe junto ao filho internado na U'T'I neonatal. houve uma significante restrição por parte dos enfermeiros quanto ao tempo para a mãe ficar junto ao bebe sendo a "interferôncia nas atividades dos elementos que assistem ao recem-nascido" a principal justificativa apontada por eles. 
Para as mães do estudo, o tempo de permanência junto ao filho internado na U'TI neonatal variava de menos de 30 minutos a mais de 60 minutos. ficando a maioria por um período de 5 a 30 minutos. Em vista disso. destacamos os seguintes comentários: "Não fico mais porque lenho medo que me mandem sair"; "Como não sabia que podia tocar nele, a gente só fica olhando"; "Nĩo adianta ficar muito tempo, a gente não pode fazer nada".

Pelos tipos de comentários feitos. podemos perceber que as mães expressam sentimentos de "ansiedade, angústia" e "conform ismo". Será válido pensar que este fato ocorre porque as mães estão quase sempre excluídas dos cuidados prestados ao belô pelos elementos da equipe de enfermagem? P'ode. mos acrescentar a essa situação a falta de "resposta" do recem-nascido prematuro e ou em estado grave a presenca de scus pais. o que traz frustração e falta de estímulos para estarem com o filho.

lissa situação pode nos levar a entender porque mais da metade das mães $(55.0 \%)$ do estudo referiram não saber como poderiam ajudar no tratamento do recém-nascido. mas quando informadas. du rante a coleta de dados. da possibilidade de realizarem alguns cuidados ao filho internado, sob a orientação e supervisão dos elementos da equipe de enfermagem. muitas se mostraram favoráveis a essa participação.

Ao considerarmos as opinióos das mães quanter aros cuidados que elas gostariam ou não gostariam de prestar ao lilho na U'Tl neonatial. verilicamos que as $20(100.0 \%)$ se mostraram favoraveis a participaça no cuidado ao filho quanto a "dar estímulo auditivo (falar)". "dar estímulo tátil (tocar. acariciar)" e "trazer chuea ou chupeta". Destas. 19 mães $(95.0 \%)$ se mostraram favoraveis a participacão quanto a "administrar a mamadeira". "verificar a temperatura corporal". "estimular a suceas" e "Irazer brinquedos (móbiles)". sendo que 18 (90.0\%) referiram a "trocar a fralda" o "administrar o leite por gavagem". e $17(85,0 \%)$ delas quanto a "lazer o curativo umbilical", "administrar a agua por gavagem" e "fazer a higione corporal".

Para S()UPJos et al (1980). os pais neecssitam de uma definição quan. to a sua função: isto os faria sentirem-se que são necessários o que a criança ainda b deles. Para isso precisam ser esclarecidos de que podem e devem ser apoiados para darem assistência à criança.

Assim. ao permitir a mãe levar brinquedos (moliles). chuca o ou chupeta para ofilho internado, está se dando excelente oportunidade para que ela se sinta útil e colaboradora na assistência ao belố. $\Lambda \mathrm{l}$ em disso. 0 ambien. te ficará mais alegre e individualizado, tornando-o assim mais "agradácel" aos olhos de todos. em especial, aos dos pais. 


\subsection{Informacão d̀ mãe}

É essencial na assistência ao recêm-nascido internado na UTI neonatal considerar a informação dada às mães, o que deve obedecer aos conceitos preventivos de CAPL $\triangle N$ N (1972) para que os pais possam se beneficiar da orientação antecipatória. Além disso, é de suma importância a rela. ção interpessoal entre os profissionais da equipe e os pais.

Quando indagamos às mães sobre o recebimento ou não de informação logo ap6s o nascimento do recém-nascido, verificamos que a grande maioria delas $(80,0 \%)$ não foi informada sobre o estado de saúde do filho.

Quanto ao recebimento de informações durante a permanência do filho na U'TI neonatal, vale destacar que um número significativo de mães (7 $35.0 \%$ ) nāo foram informadas de que o filho se encontrava internado na unidade de cuidados críticos. Dessas mães, 5 ficaram sabendo do fato somente quando da primeira visita ao recem-nascido na Unidade Neonatal.

Segundo (CARVALHO) (1984), a equipe hospitalar geralmente acredita que falar sobre a doença e tratamento pode trazer maior ansiedade e aumentar a confusão, mas que há evidências de que não conversar sobre isso com os pacientess ou responsáveis pode resultar em muitos outros distúrbios. Considerando sua experiência, a autora comenta que, a medida que os pais são devidamente informados sobre a hospitalização e procedimentos realizados. eles têm sua angústia diminuída e se tornam mais capazes para supor. tar a experiência da hospitalização. acompanhando mais de perto os filhos.

Dentre o conteúdo das informaçoes solore o filho que as mães referiam que gostariam de receber, destacamos: "condições de saúde e diagnóstico". "horário do visita" "finalidade dos aparelhos utilizados" e "identificação dos elementos da equipe". Os locais de preferencia para o recebimento dessas informações foram: a sala de parto para informação sobre a "internação do recém-nascido na U'll neonatal", o quarto para o "estado de saúde do recém. nascido" e "funcionamento da maternidade berçário e UTI neonatal", e o berçário, para "aparelhos utilizados pelo recem-nascido" e "pessoas que cuidam do recém-nascido".

Vale destacar alguns comentários feitos pelas mães que denotam suas expectativas com relação às informações sobre o filho recem-nascido: "Gostaria que ela falasse que o nenê ja estava bom"; "Que poderia ir ver o nenê no berçário ... não sabia onde era": "Queria saber aqueles fios que ficavam no peitinho dele pensava que tinha agulhas que furavam o peitinho dele"; " $E$ bom a genie saber quem está cuidando dele para não ficar tonta na hora": "Se a gente pergunta do nenê para a enfermeira ela fala para conversar com o médico, mas são tantos...": "('ostaria de saber se ela chora".

Nesice contexto para a maioria das mães $(70,0 \%)$, o médico foi referido como aquele mais indicado para fornecer quaisquer das informaçôes. Isto 
nos leva a supor que as mães se sentem mais seguras ao esclarecer suas dúvidas com o profissional médico, por ser ele o centralizador da assistência do recém-nascido.

Ao considerarmos que, para a mãe de um recém-nascido de alto risco, o momento da interação na U'TI constitui um conjunto de emoçōes como susto. medo, preocupação, entre outros, a presença de uma pessoa de confiança ao seu lado poderá ajuda-la a reunir forças para enfrentar tal situação. Nesse sentido, verificamos que, para 13 mães $(65,0 \%)$ o "marido" ou o "pai do recém-nascido" constitui clemento de apoio para estar junto a elas no momento da informação de que o filho está internado na UTI neonatal.

Ainda, no que concerne ao topico "informação às mães", quando indagamos sobre o recebimento de orientaçōes quanto à promoşào e manutenção da lactação, foi preocupante constatar que apenas uma mãe (5.0\%) foi informada sobre as "vantagens do aleitamento".

Cabe ressaltar que na nossa percepção a amamentação (? uma das principais formas de a mãe contribuir na assistência ao filho recem-nascido e conseqüentemente favorecer o vínculo entre eles. De acordo com VIE(iAS (1986), "um dos meios de reforçar ou fazer o vínculo afetivo familiar. especialmente o materno. consiste em aproximar as mães de seus filhos atraves da sua entrada no berçário e do estímulo ao aleitamento materno".

\subsection{Recursos humanos e Infra-estrutura institucional}

()s elementos que compõem a equipe da U'Tl neonatal são os médicos pediatras e ou neonatologistas, enfermeiros. teenicos e auxiliares de enformagem, nutricionista assistente social. psicólogo e em algumas instituiçoes o clérigo. Cada profissional deve responsalbilizar-se por um aspecto da assistência, atuando direta ou indiretamente junto as famílias dos receim-nascidos.

Segundo RANNA: ()KAY (1980), a família de uma criança hespilalizada é o clo de ligação entre todos os elementos da equipe, mas, quanclo não existe atuação coesa entro os vários profissionais que a compõem. a equipe não se concretiza enquanto tal, sendo que cada profissional não sabe, em geral, o que foi orientado aos pais e o que foi decidido pelos outros profissionais. Este tipo de atitude por parte dos profissionais que integram a equipe multiprofissional, alem de proporcionar conflitos e distanciament.os en l.re seus elementos reflete-se de forma negativa na assistência ao recem-nascido e propicia um atendimento fragmentado e poueo efetivo para os pais.

Constata-se ainda, que ef freqüente os familiares de pacientes hospitalizados não saberem referir quem são os elementos da equipe de saúde que estão assistindo seus pacientes, identificando-os, via de regra, pela callegoria profissional. características fisicas ou atraves da vestimenta usada. 
Para que ocorra uma integração entre os profissionais e as mães, 6 essencial que estes sejam esclarecidos quanto a composição e atribuições de cada membro da equipe multiprofissional, e que sejam apresentados a cada um pessoalmente. A esse respeito, cabe retomar algumas das declarações feitas pelas mães do presente estudo: "Acho que aquela loirinha fenfermeira": "Sei que tem um médico cuidando dele, mas não sei quem 6": "A loirinha de bculos. eu acho que é pediatra dele". $\Lambda$ falta de conhecimento ténico e de integraçáo entre os elementos que assistem as mães pode ser a causa da dificuldade de elas obterem informaçoes sobre ofilho. Isso foi verificado quando indagamos sobre qual profissional procuravam quando se dirigiam a UTI neonatial.

Verificamos que as mães que costumavam recorrer ao profissional na U'T neonatal procuravam o médico (6 māes - $30.0 \%)$ ou a enfermeira (2 mães - $10.0 \%) . \Lambda$ maioria (12 mães - $60.0 \%$ ). no entanto. respondeu que não recorria a nenhum profissional ao chegar a U'TI. Merecem destaque algumas just.ificativas feitas por essas mães: "liles ficam todos sentados quando a gente chega. seria bom se a gente não precisasse estar perguntando": "Não sou de falar muito. sempre quando eu chego estão cuidando do nenê": "Éntro direto para ver o nenê".

Quando verificamos junto as mães quais os profissionais dentre aqueles que fazem parte da equipe hospitalar que deveriam participar da assistência as mães de recem-nascidos de alto risco, observamos que o psicólogo. o assistente social e o nutricionista foram os elementos de ajuda mais referidos por 8 mães $(40.0 \%)$. (Calle destacar que seis mães desconhecem os elementos da equipe hospitalar, alem daqueles que fazem parte da equipe médi(a e de enfermagem. que assistem ao recem-nascido internado na UTI neonatial.

Ti oportuno ressaltar que para uma assistencia mais efetiva as mães de recem-nascidos internados na UT' neonatal há necessidade de que a instituicão ajude os familiares a superarem as dificuldades não so de ordem emocional e afeliva com relacão ao filho doente. mas também as dificuldades sociais e financeiras que certamente irão surgir durante a permanencia da criança na unidade neonatal. por um período indeterminado. Assim. no tocante as formas de ajuda referidas pelas mães, por parte da instituição hospitalar. destacamos o "fornecimento de passes de ônibus e lanches nos períodos de visita".

\section{CONCLUSÕES}

De acordo com o objetivo deste estudo. os resultados obtidos permitem extrair as seguintes conclusões: 
- A maioria das mães (55,0\%) não estabeleceu nenhuma forma de contato como o filho $\log$ a a naseer, e; quando ocorreu, o contato visual foi o mais freqüente $(45.0 \%)$.

- $\quad$ s mães manifestaram sentimentos de frustracão por não terem mantido contato com of filho, e os motivos referidos por elas apontam as condições físicas do recém-nascido e de si própria.

- Dentre as mães, $10,0 \%$ manteve o primeiro contato com o filho na U'TI apos 24 horas do nascimento, o que, segundo seu modo de ver, foi devido a sua limitação física e a restrição do horário de visita do berḉário.

- $\quad \Lambda s$ reaçoes emocionais referidas pelas mães decorrentes do contato visual mantido com o filho na UTI foram tristeza, pena. nervosismo, medo. surpresa, felicidade, entre outras.

- Dentre as 20 mães, apenas 2 haviam tocado o filho no primeiro contato com o recém-nascido na UTI neonatal.

- A maioria das mães permanecia menos de 30 minutos quando visitava o filho na U'TI.

- Todas as mães manifestaram desejo de participar de algum cuidado ao filho.

- As razões apresentadas por mães que não desejavam participar de determinados cuidados se referiram ao medo o ao receio de prejudicar o filho.

- $\triangle$ maioria das mães $(80,0 \%)$ não foi informada solore as condicóes do recom-nascido ao naseer enquanto que $35.0 \%$ delas não foram informadas de que o filho se encontrava internado na UTI neonalaal.

- Apenas $10.0 \%$ das mães foram informadas sobre o pessoal que cuida do recen-nascido.

- () modico foi o profissional mais indicado polas mães para dar as informaçoess sobre o recém-nascido.

- $\quad$ s mães preferem recoher as informacoos quanto a internacão do filho na U'Tl. na sala de parto; ao estado de saúde do recem-nascido e funcionamento da maternidade, beréario e U'l't, no quarto: e. solbe aparelhos e pessoas que cuidam do bebo no bercário.

- $\quad \Lambda$ s informaçóes descjadas pelas mães referem-se as condições de saúde e diagnóstico do recém-nascido. horário de visita. finalidade dos aparelhos e identificação das pessoas que cuidam do seu filho.

- () marido for a fonte de apoio mais citada pelas mães (65.0\%).

- Dentro as 20 mães, apenas uma (5.0\%) foi informada sobre as vantagens do aleitamento.

- As mães desconheciam as pessoas da equipe que cuidam do filho o a maioria delas $(60.0 \%)$ não recorria a nenhum profissional por co:asião do ingresso e permanência na U'T.

- $\quad \Lambda$ necessidade de outros prolissionais para ajudá-las, além do médieo e do 
pessoal de enfermagem, foi referida por $40,0 \%$ das mães. Essas mães citaram $o$ assistente social, o psicólogo $e$ o nutricionista.

- A ajuda durante a permanência do recém-nascido na UTI que a maioria das mães $(75,0 \%)$ espera receber são manutenção do cuidado ao bebê, possibilidade de visitar e permanecer junto ao filho e ser informada sobre as condições do recém-nascido.

\section{CONSIDERAÇÕES FINAIS}

Ao revermos toda a trajetória percorrida por qualquer uma dessas mães de recém-nascido de alto risco, da Sala de Admissão até a UTI neonatal, passando pelo Centro Obstétrico e pela Unidade de Puerpério, é possível perceber que existiram lacunas na qualidade da assistencia prestada por diferentes profissionais a essas mães, e principalmente ao recém-nascido.

Essas lacunas deixadas pelos elementos da equipe hospitalar, principalmente pelos elementos da equipe de enfermagem, não são aquelas relacionadas a eficiência e rapidez do diagnóstico elucidado, ao tratamento prescrito ou à qualidade dos cuidados e procedimentos realizados junto ao recémnascido e às suas mães; estamos falando da área expressiva da assistência onde o paciente e visto pelos profissionais de saúde como um indivíduo passivo e quase sempre desagregado de sua família. As oportunidades dadas as essas mães para que mantivessem uma interação efetiva através do ver, tocar, acariciar, conversar. e cuidar do seu bebê, retratam esta situação.

A ausência de informações e orientações relatadas por muitas mães, os obstáculos impostos por normas e rotinas da instituição que dificultam a interação precoce com o filho recém-nascido, a não possibilidade de cuidar do que lhe pertence, e, principalmente, a alienação dos profissionais envolvidos direta ou indiretam ente com a assistência ao binômio fizeram parte do arsenal utilizado pelos profissionais da equipe multiprofissional para "desumanizar" a assistência recebida pelas mães dos bebês internados na U'TI neonatal.

Tendo em vista que a assistência hospitalar é realizada por vários profissionais, ef fundamental considerar o trabalho em equipe tanto no âmbito da enfermagem como no multip rofissional. $\Lambda$ necessidade $e$ a importância do enfermeiro e dos elementos que integram a equipe multiprofissional na assistencia aos pais de recém-nascido de alto risco o justificada pela especificidade e competência profissional que cada categoria tem para atuar e interagir efetivamente com os pais em cada estágio que estes necessariamente atravessarão, entre o nascimento e durante a permanência do filho na U'TI neonatal. 
Sendo assim, os profissionais das áreas de obstetrícia e neonatologia deverão planejar a assistência a ser prestada ao recém-nascido internado na UTI neonatal e a seus familiares, levando em consideração, tamberm, as ne. cessidades e expectativas por eles apresentadas, uma vez que pudemos constatar a sua relevância através deste estudo, que explicitou o desejo da mãe em exercer o direito de cuidar do próprio filho.

BELLI, M.A. de J. Caring for mothers of newborns in the Neonatal Intensive Care Unity: experiences, feelings and expectation of mothers. Kev. Esc. Enf. USP. v.29. n.2. p. 193.210, aug. 1995

The porpuse of the study was to examine the experiences, feelings and expectation of mothers of high risk newborns. The population was a group of 20 mothers of high risk newborns of three hospitals in the City of São Paulo. Interview with the mothers was the method of data colletion containing opened and structured questions. It was verified that most of the mothers had none or only a little interaction with the newborn after delivery; the eye contact was the most referred during the staying of the newborn in the Intensive Care Unity; all of them demonstrated interest in participating in the care of the newborn and expressed the need of information concerning to the health status of the newborn, the Intensive Care Unity environment and the hospital team. Several were the feelings expressed and the motives that indicated the needs of the mothers.

UNITERMS: Mother-infant bonding. Newborn nursing. Neonatal Intensive Care Inity. High risk newborn.

\section{REFERÊNCIAS BIBLIOGRÁFICAS}

BATAGLIA, F.C.: LUBCHENCO. L.C. A practical classification of newborn infants by weight and gestation age. J. Pediatr.. v. 17, n. 4, p. 159-63, 1967.

BELLI, M.A. de J. Programa de pais participantes desenvolvido em uma unidade neonatal: experiéncia de uma enfermeira na equipe multiprofissional. In: CONGRESSO BRASILEIRO DE PERINATOLOGIA. 2. CONCRESSO LATINOAMERICANO. 4. ENCONTRO DE ENFERMAGEM PERINATAL, 8. Porto Alegre, 1988. Resumos. Porto Alegre. Sociedade Americana de Perinatologia, 1988, p. 101.

BELLI, M.A. de J.; TSUNECHIRO, M.A. Os pais em UTI neonatal: expectadores ou participantes? Apresentado no 4. Encontro Estadual em Terapia Intensiva. Såo Paulo. 1989.

BELLI, M.A. de J.; TSUNECHIRO, M.A.. UTI neonatal: possibilidade da manutenção do vínculo mae-filho. In: CICLO DE DEBATES SOBRE ASSISTÊNCIA DE ENFERMAGEM. ENFTEC, São Paulo. 1990. Anais. Sao Paulo, Centro de Estudos em Enfermagem "8 de Agosto". Hospital "9 de Julho". 1992. p. 438-41. 
BRASIL. Constituiçáo, 1988. Constituiçáo da República Federativa do Brasil. Título 2, cap. 2. Art. 7, Inciso 18. Brasilia, Senado Federal, 1988. p. 13.

CAPLAN, G. An approach to community mental health. New York, Grune \& Stratton, 1972.

CARVALHO, M.M.B. Informação: um direito dos pais. Pediatria, v. 6, n. 2, p. 84-5, 1984.

COSTA, C.F. Gravidez na adolescéncia. In: ALVES FILHO, N. CORREA, M.D. Manual de perinatologia. Rio de Janeiro, Médica e Científica. 1990. cap. 31, p. 407-13.

CRANLEY, M.S. Perinatal risk. Jogn. Nurs., v. 12, n. 3, p. 8.13, 1983.

DA POIAN. V. da et al Avaliaçáo da idade gestacional do recém-nascido (RN), pelo método de Capurro. por enfermeiros e médicos que atuam na unidade de neonatologia do Hospital de Clínicas de Porto Alegre, UIN-HCPA Rev. Gaúcha Enf, v. 5, n. 2, p. 287-98. 1984

FISER. D.H. et al. Service for parenteral stress reduction in a pediatric ICU. Crit. Care Med. v. 12, n. 6, p. 504.7, 1984

IRWIN. S ; LLOYD.STILL. D. The use of groups to mobilize parenteral strenghs during hospitalization of children. Child Welfare. v. 53. n. 5. p. 305.12. 1987.

KANG. R. El processo de familiarización de la madre y el nino. In: BARNARD. K.E. et al. Las primeras relaciones entre padres y el niño. Washington. Organización Panamericana de La Salud. 1982. cap. 2. p 44-7.

KLAUS. M.H ; KENNEL. J.H. L.a relación madre.hijo. Buenos Aires. Editorial Médica Panamericana. 1978.

MALDONADO, M.T. Psicologia da gravidez 6. ed., Petrópolis. Vozes, 1984 cap. 1. p. 65-100 Aspectos psicológicos da gravidez do parto e do puerpério: aspectos psicológicos do puerpério e os primórdios do relacionamento pais-bebés.

MONT AGÚ. A. Tocar: o significado humano da pele. São Paulo, Summus. 1988.

RAMOS, T.A.G.: MORAES, E Papel da enfermeira junto a maes e crianças hospitalizadas. Rev Bras Enf. v. 29. n. 2, p. 45-55, 1976.

RANNA. W : OKAY. Y. Grupos de pais de crianças e da equipe multiprofissional e sua influência nas diretrizes da enfermaria geral de um hospital infantil. Pediatria (Sao Paulo). v. 2. n. 2.p. 184-90, 1980.

REICHLE, M.J. Psychological stress in intensive care unit. Nurs Digest. v. 3. n. 3. p. 12-5. 1975

RUBIN, R. Puerperal change. Nurs. Outlook. v. 9. n. 12.p. 753-5. 1961

SÃO PAULO (Estado). Secretaria de Estado da Saúde. Sistema Unificado e Descentralizado de Saúde - SUDS/SP. Programa de atendimento integral à saúde do adolescente. São Paulo 1989

SOUPIOS, M. et al Aspectos da enfermagem no tratamento intensivo em um hospital geral. Clin Pediat. Amer. Norte. v. 27. n. 3. p. 639.53. 1980

SULLIVAN, R. et al. Determining a newborn's gestacional age. MCN. v. 4. n. 1. p. 38.45. 1979. 
VERNY. T.; KELLY. J. A vida secreta da criança antes de nascer. Såo Paulo. C. J Salmi. 1981.

VIEGAS. D. Aspectos psicológicos da assisténcia ao recém-nascido. In: VIEGAS, D :

VILHENA-MORAES, R. Neonatologia clínica e cirúrgica. Rio de Janeiro. Atheneu 1986 v 1. cap. 29. p. 275-97.

ZIEGEL, E.E.: CRANLEY. M.S Enfermagem obstétrica. 8 ed. Rio de Janeiro. Interamericana. 1985. cap. 24. p. 438.52: Assisténcia de enfermagem à familia no pós-parto: respostas psicossociais. (a)

ZIEGEL, E.E.: CRANLEY. M.S Enfermagem obstétrica. 8 ed. Rio de Janeiro, Interamericana. 1985. cap 29. p. 570-605: Recém-nascido de alto risco características e assisténcia de enfermagem. (b) 